\title{
The effectiveness of group combined intervention using animal-assisted therapy and integrated elderly play therapy
}

\author{
Taeyoung Kil ${ }^{1}$, Hak-man $\mathrm{Kim}^{2^{*}}$ and Minkyu Kim ${ }^{3,4^{*}}$ \\ ${ }^{1}$ Institute of Agricultural Science, Chungnam National University, Daejeon 34134, Korea \\ ${ }^{2}$ Department of Social Welfair, Woosong University, Daejeon 34606, Korea \\ ${ }^{3}$ Division of Animal and Dairy Science, Chungnam National University, Daejeon 34134, Korea \\ ${ }^{4}$ MK Biotech Co., Ltd., Daejeon 34134, Korea
}

\begin{abstract}
The purpose of this study was to investigate the effects of group combined intervention that combined animal-assisted therapy and integrated elderly play therapy on the depression, self-esteem, and emotional expression of geriatric patients residing in nursing homes. This was achieved by providing cognitive, physical, and emotional activities and social interaction at the same time. The group combined intervention method was applied to twelve elderly patients (six in the control group, six in the experimental group) aged 65 or older who live in a nursing home for the elderly in C province, from May 3, 2019 to June 21,2019 , for a total of 8 times (once a week, 50 minutes at a time). The quantitative evaluation was analyzed through SPSS 21.0 for comparison before and after the program was implemented, using the Korean version of the depression and the self-esteem scale. The qualitative evaluation compared emotional expression pre-test and post-test. The major results of the study were as follows: First, the group combined intervention was effective in reducing depression levels of the experimental group among the elderly patients. Second, it was effective in improving the self-esteem of the experimental group among the elderly patients. Third, it showed a significant difference in the emotional expression of the experimental group among the elderly patients. Therefore, it was found that group combined intervention reduces depression and improves self-esteem and emotional expression of the elderly. Based on these results, it is hoped that this study will be a cornerstone in the development of concrete programs for the benefit of elderly patients living in facilities.
\end{abstract}

Keywords: Animal-assisted therapy, Depression, Group combined intervention, Integrated elderly play therapy, Self-esteem

\section{Background}

As of 2017, the elderly population in Korea accounted for $14.2 \%$ of the total population $(7,115,000$ people) and has led Korea to become the aged society. Due to a rapid increase in the elderly population and alienation from family, problems of the elderly such as depression, economic anxiety, and social isolation are becoming more serious. In order to cope with changes in the social structure owing to emergence of the nuclear family, increase in instances of the elderly living alone, and weakening of the healthcare system, the long-term care insurance system was introduced in 2008 by the central and local governments. They expanded the care facilities for

Received: Nov 2, 2019 Revised: Nov 8,2019 Accepted: Nov 8,2019

"Corresponding author: Minkyu Kim, Division of Animal and Dairy Science, Chungnam National University, Daejeon, 34134, Korea.

Tel: +82-42-821-5773, E-mail: kminkyu@cnu.ac.kr

Hak-man Kim, Department of Social Welfair, Woosong University, Daejeon 34606, Korea.

Tel: +82-42-630-9847, E-mail: hakman@hanmail.net

This is an Open Access article distributed under the terms of the Creative Commons Attribution Non-Commercial License (http://creativecommons.org/licenses/by$\mathrm{nc} / 4.0 /$ ) which permits unrestricted non-commercial use, distribution, and reproduction in any medium, provided the original work is properly cited.

Copyright (C) 2019 Korean Society of Animal Science and Technology. 


\section{JAST}

the elderly in line with the increasing demand. In this short period, a quantitative infrastructure of facilities was established, but conflicts the elderly experienced mentally were not considered. Issues such as changes in lifestyle, individual differences according to the health condition, decrease in self-esteem due to difficulties and restrictions in daily life, alienation from the family, and depression caused by the death of a spouse were not given enough attention [1].

Among the elderly, depression is caused due to stress, economic problems, loss of social role, health conditions, and social isolation due to changes in family relations. The degree of geriatric diseases became more serious with the increase in age among the elderly in facilities in comparison to the general elderly population [2,3]. In a study on self-esteem, the elderly living in facilities were more depressed than hospitalized patients, had lower self-esteem, and had negative correlations with depression and self-esteem [4-6]. However, intervention programs focusing on specific variables such as depression and self-esteem are relatively insufficient, and it is very important to provide a stimulating environment for active intervention in psychosocial difficulties experienced by the elderly in facilities [7]. In several studies, it was proved that group combined intervention including objective activities was effective in reducing depression and improving the self-esteem of elderly people with geriatric disease or nursing home elderly [5,6,8-12]. In the clinical field, it has been observed that the elderly will express and reflect their emotions while participating in various activities, which provides opportunities for communication among participating members and promotes psychological and emotional stability through the establishment of an emotional support system $[13,14]$.

In the past 10 years, various domestic and foreign studies have proposed numerous approaches to combine cognitive rehabilitation, occupational therapy, physical activity, music therapy, art therapy, recollection therapy, recreation, animal meditation, etc. in order to be more effective interventions [15-17]. The combined intervention program to improve health conditions and quality of life of patients living in geriatric nursing homes is divided into four categories: cognitive activity, physical activity, emotional activity, and social interaction activity $[14,16]$. It is a combined or complex method of non-drug therapy applied to the subjects. Physical, mental, and social rehabilitation of the elderly can improve social function, mental state, and quality of life as well as reduce national costs $[18,19]$.

In animal-assisted therapy (AAT), therapy dogs interact with clients in animal assisted interventions, to enhance therapeutic activities and well-being including the physical, cognitive, behavioral and socio-emotional functioning of clients. Well trained therapy dogs exhibit the behavior that human clients construe as friendly and welcoming [20]. Especially, AAT can improve physical and mental health; alleviate loneliness; reduce stress, anxiety, and de- pression; promote social interaction through exercise and playfulness; unconditional love and affection for the elderly. Caring for pets is safer than caring for children, restores the active growth and self-esteem of the elderly, and provides them with valuable companions [21]. Integrated elderly play therapy (IEPT) is focused on maintaining an optimal state to prevent or solve psychological and social difficulties by recovering lost abilities or memories. This is achieved by actively participating in play behavior by being convinced of the therapeutic power of play, and consists of an integrated approach involving activities such as music, art work, language or literature, physical exercise, cognitive games, living area, and traditional play $[22,23]$.

The complex approach of non-drug therapy has been able to address various requirements of elderly patients, caregivers, and therapists according to the complexity and proreess of geriatric diseases. It has been of increasing interest in clinical fields over the past few years [22,24].

In particular, several studies have been actively conducted to prevent and treat cognitive disorders, mild cognitive disorders, and geriatric diseases without dementia $[9,11]$. Many studies showed that the combined intervention of AAT, occupational therapy, play therapy and social interactions was effective in improving quality of life through maintenance of cognitive function, independence in the community, recovery of self-esteem, and reduction of depression in the elderly $[8,16,25,26]$. The complex intervention of AAT for the elderly with mental pain presented the most reasonable results in the clinical environment [27]. However, it is difficult to find clinical studies applying complex intervention method to the elderly living in elderly nursing homes with various functional disabilities.

The combined intervention of AAT and play therapy, which has been conducted in various domestic and foreign studies so far, has been found to have a positive effect on the self-esteem of the elderly, also reducing depression $[8,15,26,28]$. However, it was pointed out that the intervention method is not described in detail and the activities that stimulate the interest and active participation of the elderly are insufficient. In addition, intervention for the elderly in facilities is different depending on the institution. As the people who provide the guidelines, curriculum, and programs differ, qualitative management of the intervention contents is necessary [12].

In order to complement the limitations of previous studies and accumulate academic and clinical data, it is expected that the combined intervention of AAT that aids in the treatment and recovery of mind and body through interaction with animals and IEPT can be an interesting and effective approach.

So far, group combined intervention has been conducted for the precedue of each of the social interaction activities that preserve residual functions, by preventing planned and purposeful phys- 
ical activities to improve physical health, cognitive training that reflects the specific cognitive function and requires guidance by the therapist, emotional activities that mainly apply recall therapy, and depression that is related to damage of the cognitive function [15]. As suggested by Fabel et al. [29], synergies were provided to improve cognitive function and emotion for more positive effects of complex intervention. Environments that stimulate cognitively even if physical activity is minimized were also provided. In addition, the use of animals enabled expression of intimate emotions and social interaction to occur more effectively. Therefore, two single intervention methods were combined into a program to reduce depression among the elderly and improve self-esteem. In addition, this study encouraged the individual emotional expression of the elderly participating in the study by providing communication opportunities and enhancing emotional stability among members. This was done in order to supplement quantitative research by using the qualitative research method suggested by a researcher [14].

This study will investigate the effects of group combined intervention including purposeful activities and social interaction on the self-esteem, emotional and mental health of elderly patients with geriatric diseases living in elderly nursing homes.

\section{Materials and Methods}

\section{Subject of study}

The subjects of this study were elderly geriatric patients who wanted to participate in the program and were living in a nursing home for the elderly in $\mathrm{C}$ province. As shown in Table 1, participants of the program were twelve elderly patients aged 65 or older. Six were assigned to the experimental group, and the other six to the control group. Of all the subjects in the experimental group, two were men and four were women, and the average age was 79.5 years.
Three of the subjects were agnostics, two were Christians, and one was Buddhist. Three of them were elementary school graduates, two of them were middle school graduates and one of them was a high school graduate. The income level of subjects was three were middle class, two were lower-middle class and one of them was upper-middle class. As the subjects had geriatric diseases and were unable to walk, they were mostly able to participate in wheelchair activities. The control group also participated in six elderly geriatric patients were living in a nursing home that was tested for homogeneity. There were no issues with the combined intervention (AAT and IEPT) program and there was no difficulty in demonstrating cognitive ability and communication.

\section{Research design and data collection}

To verify the effectiveness of the intervention program that combines AAT and IEPT, the difference before and after education between the experimental group and the control group was compared using the non-equivalent control group pre- and post-test. As demonstrated in Table 2, the pre-test was conducted on the day of intervention, and the post-test was conducted at the time of intervention. This study provided a 50-minute program once a week as a combined intervention method. The researcher, who is an expert in AAT and certificated in elderly play therapy, and currently in charge of individual and group programs at a geriatric hospital, cooperated with program design, progress, observation and evalua-

Table 2. Effective verification model of group combined intervention

\begin{tabular}{lccc}
\hline \multicolumn{1}{c}{ Group } & Pre-test & Intervention & Post-test \\
\hline Experimental group & $\mathrm{O}_{1}$ & $\mathrm{X} 1^{1)}$ & $\mathrm{O}_{2}$ \\
Control group & $\mathrm{O}_{3}$ & - & $\mathrm{O}_{4}$ \\
\hline
\end{tabular}

${ }^{11}$ Multimodal interventional program.

Pre-test, the day of intervention; Post-test, end of intervention.

Table 1. General characteristics of the experimental group

\begin{tabular}{|c|c|c|c|c|c|c|c|}
\hline Participants & Gender & Age & Religion & Education & Income level & Geriatric diseases & Activity characteristic \\
\hline A & M & 86 & Christian & $\begin{array}{l}\text { High school } \\
\text { graduate }\end{array}$ & Lower-middle & $\begin{array}{l}\text { Hypertension, } \\
\text { diabetes, stroke }\end{array}$ & $\begin{array}{l}\text { The lower limb function is inconvenient, but the } \\
\text { upper limb function is good and can be operated } \\
\text { by wheelchair. }\end{array}$ \\
\hline B & M & 75 & Christian & $\begin{array}{l}\text { Middle school } \\
\text { graduate }\end{array}$ & Middle & $\begin{array}{l}\text { Hyperthyroidism, } \\
\text { hypernasitis, } \\
\text { hypofunction }\end{array}$ & $\begin{array}{l}\text { Cognitive state and communication is good, and } \\
\text { it is possible to take a wheelchair. }\end{array}$ \\
\hline C & $\mathrm{F}$ & 76 & Atheist & $\begin{array}{l}\text { Elementary school } \\
\text { graduate }\end{array}$ & Middle & Stroke (hemiplegia) & $\begin{array}{l}\text { Although she has mild cognitive impairment, she } \\
\text { can participate in the program in a wheelchair. }\end{array}$ \\
\hline $\mathrm{D}$ & $\mathrm{F}$ & 81 & Buddhist & $\begin{array}{l}\text { Elementary school } \\
\text { graduate }\end{array}$ & Lower-middle & $\begin{array}{l}\text { Diabetes, } \\
\text { minor dementia }\end{array}$ & $\begin{array}{l}\text { Sometimes she show abnormal behavior, but } \\
\text { general communication is possible, and she can } \\
\text { act as normal walking. }\end{array}$ \\
\hline E & $\mathrm{F}$ & 78 & Atheist & $\begin{array}{l}\text { Elementary school } \\
\text { graduate }\end{array}$ & Upper-middle & Stroke & $\begin{array}{l}\text { A strong will to rehabilitate and active in a } \\
\text { wheelchair. }\end{array}$ \\
\hline $\mathrm{F}$ & $\mathrm{F}$ & 81 & Atheist & $\begin{array}{l}\text { Middle school } \\
\text { graduate }\end{array}$ & Middle & $\begin{array}{l}\text { Cerebral infarction, } \\
\text { wrist fracture }\end{array}$ & $\begin{array}{l}\text { A week after entering the hospital, she have a } \\
\text { little inconvenience and can participate in the } \\
\text { program. }\end{array}$ \\
\hline
\end{tabular}

M, male; F, female. 
tion. In addition, one assistant with a clinical certificate, two social workers, one occupational therapist, two physical therapists and four care workers were involved to consider the drop-out and to apply effective play therapy to the elderly even after the program had ended. The dogs were vaccinated and dewormed in advancetwo poodles over 1 year old and two mixed breeds who were 2 years old were guided by pet therapy experts to participate in the program with sufficient rest, so that they were not exposed to stress caused by the program.

Data was collected from May 3 to June 21, 2019 with the help of one assistant, two social workers, and three care workers. Data related to the study was collected using a structured questionnaire. Prior to data collection, the researcher's identity was revealed to the participants from a standpoint of ethical consideration, and the purpose of the study was specifically explained. The subjects involved were willing to actively participate in the program by informed consent.

\section{Measurement tools}

\section{Depression}

The Korean version of the depression scale, Geriatric Depression Scale Short Form-Korea (GDSSF-K) developed by Kee [30], was used as a tool to test the degree of depression. GDSSF-K is a standardized scale used for Koreans, and its simple implementation and scoring method makes it advantageous when being applied to the elderly. It consists of 15 questions in total, the total score is 15 out of 15 , and the cut-point is based on 5 points. The higher the score, the higher the degree of depression. In this study, Cronbach's $\alpha$ was 0.965 .

\section{Self-esteem}

Self-esteem is an evaluation of one's self-concept, which is based on one's overall evaluation of themselves, as they accept themselves positively and perceive themselves as valuable human beings.

This method was developed by Rogenberg [31] and translated by Jon [32], and one of the biggest advantages of this scale is that it has been used for a long time in the wide group and has been proven to have predictive and constructive validity. The scale used in this study consists of 10 questions, five of which were positive and five were negative. For positive questions, the score was measured on a 5 -point Likert scale ( 1 = not at all, 5 = very yes $)$, and negative questions were scored by reverse coding. The score ranged from 0 to 40 , which means that higher the score, higher the self-esteem. In this study, Cronbach's $\alpha$ of self-esteem was 0.937 .

\section{Qualitative research tools: classification of emotions using words}

Emotional word classification is used to provide opportunities for communication among members and to promote emotional stability. This is accomplished by checking the basic category of an individual's emotions, using words frequently used by Koreans in their emotional expression as a basic list. The five emotional words used by the program participants were expressed on a 100-point basis, and the 30 emotions expressed by six elderly patients in each group were classified into positive and negative emotional words, as demonstrated in Table 3. This method was used to complement quantitative evaluation in various clinical settings [14,33].

\section{Group combined intervention program (AAT and IEPT)}

The group combined intervention program is a combination of two single intervention methods: AAT and IEPT. Based on the results of verifying the effectiveness of combined intervention at home and abroad to help elderly patients living in nursing homes recover their self-esteem and reduce depression, based on the clinical analysis and evidence collection [16,24].

Each session comprised a single intervention program combined with cognitive, physical, emotional, and social interaction activities. The contents of the program are displayed in Table 4.

\section{Results}

\section{Comparison of depression levels before and after im-} plementing the group combined intervention program On comparing the results of the experimental and control group before and after the implementation of the group combined intervention program, we can observe that the average changes in depression levels exhibited by the experimental group were more substantial than the average changes exhibited by the control group. The mean values and standard deviation of each group were analyzed to determine the effects of the group combined intervention program on the depression levels of the elderly patients. As demonstrated in Table 5, the depression levels of the experimental

Table 3. Emotional word classification

\begin{tabular}{ccc}
\hline Positive emotional expressions & Neutral emotional expressions & Negative emotional expressions \\
\hline $\begin{array}{c}\text { Enjoyment, pleasure, happiness, satisfaction, } \\
\text { warmth, sense of accomplishment, expectation, } \\
\text { ecstasy, interest, excitement, impressive, } \\
\text { interesting etc. }\end{array}$ & Surprise, hardness, flat, extraordinary etc. & $\begin{array}{c}\text { Disappointment, sadness, stifling, frustration, } \\
\text { unhappiness, irritability, lonelines, dreariness, } \\
\text { anger, fear, unfairness, regret, terrible, } \\
\text { painfulness, guilt, suffering, worry, discomfort, } \\
\text { no desire, futility, etc. }\end{array}$ \\
\hline
\end{tabular}


Table 4. Contents of group combined intervention program

\begin{tabular}{|c|c|c|c|}
\hline \multirow[t]{2}{*}{$\begin{array}{l}\text { Stage } \\
\text { (session) }\end{array}$} & \multirow[t]{2}{*}{ Goal } & \multicolumn{2}{|r|}{ Combined intervention activity and integration foundations by session } \\
\hline & & Session & Activities \\
\hline \multirow[t]{2}{*}{$\begin{array}{l}\text { Initial } \\
(1-2)\end{array}$} & \multirow{2}{*}{$\begin{array}{l}\text { Lapo formation } \\
\text { Ice-breaking to form intimacy } \\
\text { and trust between group } \\
\text { members, play therapists and } \\
\text { therapy dogs }\end{array}$} & 1 & $\begin{array}{l}\text { - Making name tag/Introducing myself and learning names of friends (IEPT-social interaction } \\
\text { activity) } \\
\text { - Who are you?/Singing (IEPT-emotional activity) }\end{array}$ \\
\hline & & 2 & $\begin{array}{l}\text { - Greeting a friend/singing rounds (IEPT-social interaction activity) } \\
\text { - Coloring the pictures of the puppies on the printing paper (IEPT-emotional activity) } \\
\text { - Explaining and sharing feelings on the therapy dogs (AAT-cognitive activity) }\end{array}$ \\
\hline \multirow[t]{4}{*}{$\begin{array}{l}\text { Middle } \\
(3-6)\end{array}$} & $\begin{array}{l}\text { The approaching activities of } \\
\text { combined intervention }\end{array}$ & 3 & $\begin{array}{l}\text { - Ensemble with maracas/our puppy is a Shaggy Puppy (IEPT-physical activity) } \\
\text { - Greeting the therapy dogs and skin ship (AAT-emotional activity) }\end{array}$ \\
\hline & \multirow{3}{*}{$\begin{array}{l}\text { - Cognitive activity } \\
\text { - Physical activity } \\
\text { - Emotional activity } \\
\text { - Social interaction activity }\end{array}$} & 4 & $\begin{array}{l}\text { - Hansam Play and chair exercises (IEPT-physical activity) } \\
\text { - Remembering therapy dogs (AAT-cognitive activity) } \\
\text { - Learning how to brush and massage a therapy dog (AAT-social interaction activity) }\end{array}$ \\
\hline & & 5 & $\begin{array}{l}\text { - Hands-on games/prevention of dementia by finger yoga (IEPT-physical activity) } \\
\text { - Sending compliments and words of blessing (IEPT-social interaction activity) } \\
\text { - Listening to music with a therapy dogs/flower waltz (AAT-social interaction activity) }\end{array}$ \\
\hline & & 6 & $\begin{array}{l}\text { - Talking about traditional story 'The dog and the cat' (IEPT-cognitive activity) } \\
\text { - Making a snack for therapy dogs (AAT-emotional activity) } \\
\text { - Sympathizing with the therapy dogs (AAT-social interaction activity) }\end{array}$ \\
\hline \multirow[t]{2}{*}{$\begin{array}{l}\text { Final } \\
(7-8)\end{array}$} & $\begin{array}{l}\text { Activity and preparation for } \\
\text { finishing the program }\end{array}$ & 7 & $\begin{array}{l}\text { - Therapy dogs grooming/collage (IEPT-physical activity) } \\
\text { - Matching emotions with the therapy dogs (AAT-social interaction activity) } \\
\text { - Making memory albums (IEPT-emotional activity) }\end{array}$ \\
\hline & $\begin{array}{l}\text { Discussion and exchanged } \\
\text { opinions about the program, } \\
\text { sharing joyful experiences and } \\
\text { precious memories, feedback } \\
\text { and reviews }\end{array}$ & 8 & $\begin{array}{l}\text { - You are flower, I am flower (IEPT-emotional activity) } \\
\text { - Share thoughts on the participation of the integrated intervention and closing }\end{array}$ \\
\hline
\end{tabular}

IEPT, integrated elderly play therapy; AAT, animal-assisted therapy.

Table 5. The effects of group combined intervention program on depression in elderly patients

\begin{tabular}{cccc}
\hline Variables & $\begin{array}{c}\text { Group } \\
(\mathbf{n}=\mathbf{6} \text {, each group) }\end{array}$ & $\begin{array}{c}\text { Pre-test } \\
\text { (Mean } \pm \text { SD) }\end{array}$ & $\begin{array}{c}\text { Post-test } \\
\text { (Mean } \pm \text { SD) }\end{array}$ \\
\hline Depression & Experiment & $0.84 \pm 0.11^{\mathrm{a}}$ & $0.62 \pm 0.13^{\mathrm{b}}$ \\
& Control & $0.82 \pm 0.14^{\mathrm{a}}$ & $0.83 \pm 0.12^{\mathrm{a}}$ \\
\hline
\end{tabular}

a,b Within rows, values with different superscripts are significant different $(p<0.05)$.

Table 6. The effects of group combined intervention program on selfesteem in elderly patients

\begin{tabular}{cccc}
\hline Variables & $\begin{array}{c}\text { Group } \\
(\mathbf{n}=\mathbf{6} \text {, each group) }\end{array}$ & $\begin{array}{c}\text { Pre-test } \\
\text { (Mean } \pm \text { SD) }\end{array}$ & $\begin{array}{c}\text { Post-test } \\
\text { (Mean } \pm \text { SD) }\end{array}$ \\
\hline Self-esteem & Experiment & $3.38 \pm 0.47^{\mathrm{a}}$ & $3.71 \pm 0.32^{\mathrm{b}}$ \\
& Control & $3.22 \pm 0.45^{\mathrm{a}}$ & $3.28 \pm 0.41^{\mathrm{a}}$ \\
\hline
\end{tabular}

a,b Within rows, values with different superscripts are significant different $(p<0.05)$.

group significantly decreased by $0.84 \pm 0.11$ and $0.62 \pm 0.13$, respectively $(p<0.05)$.

\section{Comparison of self-esteem before and after implement- ing the group combined intervention program}

In Table 6, on comparing the results of the experimental and control group before and after the implementation of the group combined intervention program, we can observe that the average changes in self-esteem exhibited by the experimental group were more substantial than the average changes exhibited by the control group. The results on comparing the self-esteem scores based on the scale by Rogenberg [30], were as follows. The mean values and standard deviation of each group significantly increased to $3.38 \pm$ 0.47 and $3.71 \pm 0.32$, respectively $(p<0.05)$.

\section{Qualitative study: expression of emotions using words}

The application of group combined intervention in this study has a small number of samples and is limited to measure only quantitative evaluations due to the nature of psychological intervention. Therefore, the expression of emotion through words before and after the program was analyzed to supplement this. Five emotions were selected by each individual member of the experimental and control group and the degree of emotion was expressed on a 100 -point basis. Among the 30 emotions expressed by the six elderly patients in the experimental group, 21 were positive, 3 were neutral, and 6 were negative. The most common positive expressions in the experimental group were happiness, enjoyment, interest, pleasure, excitement, whereas negative expressions were sadness, misfortune, painfulness, frustration, and regret. Among the 30 emotions expressed by the six elderly patients in the control group, 7 were positive, 11 were neutral, and 12 were negative. The most common negative expressions in the control group were irritated, frustrated, angry, and unmotivated. The results of comparing and analyzing the pre-test and post-test scores by dividing the 
Table 7. The change of emotion before and after the application of group combined intervention program participant in elderly patients

\begin{tabular}{lccc}
\hline Variables & $\begin{array}{c}\text { Pre-test } \\
\text { (Mean } \pm \text { SD) }\end{array}$ & $\begin{array}{c}\text { Post-test } \\
\text { (Mean } \pm \text { SD) }\end{array}$ & t-value \\
\hline $\begin{array}{l}\text { Positive } \\
\text { emotion }\end{array}$ & $38.15 \pm 6.56^{\mathrm{a}}$ & $57.17 \pm 6.89^{\mathrm{b}}$ & 2.581 \\
$\begin{array}{l}\text { Negative } \\
\text { emotion }\end{array}$ & $52.16 \pm 9.65^{\mathrm{a}}$ & $39.15 \pm 8.96^{\mathrm{b}}$ & -1.961 \\
\hline
\end{tabular}

${ }^{a, b}$ Within rows, values with different superscripts are significant different $(p<0.05)$.

emotional words expressed by the elderly into positive and negative expressions are demonstrated in Table 7.

\section{Discussion}

The purpose of this study was to investigate the effects of group combined intervention on depression and self-esteem of geriatric patients living in a nursing home for the elderly in $\mathrm{C}$ province. The group combined intervention program combining AAT and IEPT was implemented once a week for 50 minutes. It included objective cognitive, physical and emotional activities as well as social interaction activities, and was conducted over 8 sessions. The subjects of this study were twelve patients aged 65 or older. Six patients were assigned to the experimental group and six to the control group. To verify the effectiveness of the combined intervention, the Korean version of the depression scale for the elderly developed by Rogenberg [31] was used. Self-esteem was analyzed using the scale adapted by Jon [32]. For qualitative analysis, emotional word classification was used, and the main results are as follows.

First, the group combined intervention program combining AAT and IEPT was effective in reducing depression levels of the elderly patients. These results are based on the results of studies by Lee et al. [15] and Kim et al. [12], who applied the combined intervention method to elderly patients with early dementia, and Kim et al. [6] who applied the combined intervention method to the elderly with high depression levels using elderly welfare centers. It can be inferred that this method helps to maintain an optimal state and aids in preventing or solving psychosocial difficulties. This is achieved by active participation of the study subjects and with confidence in the application of AAT and IEPT, which are single intervention methods.

Second, the group combined intervention program combining AAT and IEPT was effective in improving the self-esteem of the elderly patients. The results are based on results by Burgener et al. [8], which showed that this study was effective in improving self-esteem through positive changes, such as the application of complex intervention on the elderly with low self-esteem using mental health centers Kim [25] and in the case of Kim [28] who applied complex intervention on the elderly living alone. There was also a reported improvement in social behavior by applying complex intervention on the elderly with early dementia. Thus, we can infer that it is very important to optimize the power of intervention methods and provide a rich environment by applying an essential model based on complex intervention in order to improve factors such as self-esteem, which are necessary for a healthy and balanced mental state.

Third, the combined intervention program implemented in this study showed a significant difference in the emotional expression of the elderly patients before and after the program. The elderly patients who were assigned to the experimental group expressed a lot of positive emotions, using words such as happiness, pleasure, interest, enjoyment, and excitement. It provided them an opportunity to experience various emotions by expressing the negative feelings they had suppressed.

Based on the summarized results, our suggestions are as follows.

First, psychotherapy with the intervention of the treatment assistance dogs was not harmful or negative to the elderly having mental pain, and the most reasonable result was demonstrated in clinical environments requiring intervention [27]. However, in the past, single intervention AAT was generally combined with occupational therapy, art therapy, music therapy, spiritual training, and exercise. As this study demonstrates, IEPT adopted as a single intervention method can play an important role as a new alternative for improving lost abilities, recovering memories, fostering positive interpersonal relationships and improving social function because integrated approach activities such as music, art work, language literature, physical exercise, cognitive games, life, traditional play, and hand-on play are possible. Therefore, it is necessary to expand the combined intervention methods of AAT and IEPT as they are preventively effective, highly accessible, and clinically significant.

Second, it is very important to know which non-drug therapy is mediated as well as how it is mediated in a group combined intervention [34]. It is demonstrated that structured group intervention can eliminate negative factors to improve social participation and relationships of the elderly [35]. Despite the fact that competence of experts in group intervention is very important, there are not many studies that objectively determine this. Consequently, multidisciplinary clinical studies should be conducted in order to apply complex intervention of AAT and IEPT to various groups. Also, the most important factor for group combined interventions to be successful is the need to cultivate professionals who will provide professional services. This can be facilitated through the interaction of therapists and subjects in various fields of study.

Third, after introducing the treatment dogs at the nursing home, it was deduced that the therapeutic benefits to the elderly patients' mental health could be extended by increasing the opportunity of interactions with the caregivers and animals as well as elderly pa- 
tients having dementia [36]. In addition, the use of therapy animals in institutions and residential facilities and the combined intervention including animals demonstrated an increase in social interaction and language use in comparison to traditional treatments. It was also found that they served as motivators to encourage active participation in programs [26]. Other studies have been continuously trying to implement alternative treatment strategies that bring humans and animals together, as it also allows elderly people to care for weaker animals in a pleasant environment, fostering social contact, spiritual training, exercise, and play [37]. Therefore, it is anticipated that discussions on policy support will soon make it possible to provide programs for the elderly in various institutions or facilities that require group combined intervention.

This study is meaningful as it demonstrates the possibility of effective and appropriate therapeutic intervention and fusion research, by verifying the effect on depression and self-esteem of geriatric patients residing in geriatric nursing homes, applying the group combined intervention of AAT and IEPT. However, the limitations of this study for generalization of the results are as follows.

For generalization and validation of the study, appropriate samples were obtained and tests were conducted before and after implementing the intervention methods to compare both groups considering the expansion of subjects and socio-demographic characteristics. However, it is expected that pre-tests, post-tests, and follow-up tests will be conducted to verify the continuous effect of complex intervention in future studies. In addition, it is suggested that further studies should be conducted on the experimental group and strict allocation methods need to be utilized to determine the value and cost-rate of group combined intervention.

\section{Competing interests}

No potential conflict of interest relevant to this article was reported.

\section{Funding sources}

This work was supported by research fund of Chungnam National University.

\section{Acknowledgements}

Not applicable.

\section{Availability of data and material}

Upon reasonable request, the datasets of this study can be available from the corresponding author.

\section{Authors' contributions}

Conceptualization: Kil TY.

Data curation: Kim MK.
Formal analysis: Kim MK.

Methodology: Kil TY, Kim HM.

Software: Kim MK.

Validation: Kim HM.

Investigation: Kil TY.

Writing - original draft: Kil TY.

Writing - review \& editing: Kil TY, Kim HM, Kim MK.

\section{Ethics approval and consent to participate}

Not applicable.

\section{ORCID}

Taeyoung Kil

Hak-man Kim

https://orcid.org/0000-0003-4143-449X

Minkyu Kim

https://orcid.org/0000-0002-4910-4172

https://orcid.org/0000-0002-9259-8219

\section{References}

1. Kang MS. A psychological study on the adaptation process of inpatients in nursing homes. Korean Soc Gerontol Soc Welf. 2012;2:58-80.

2. Blazer D. Depression in the elderly. N Engl J Med. 1989;320:164-6.

3. Lee JH. The effect of group music program on depression in the institutionalized elderly. J Korean Gerontol Nurs. 2001;3:42-52.

4. Choi YA. A survey on the depression, self-esteem and health behavior of the aged. Korean J Gerontol Soc Welf. 2003;21:2747.

5. Park GJ, Lee JH, Bae KE, Kang YH, Song HS. Self-esteem and depression of elders in welfare facilities.J Korean Gerontol Nurs. 2007;9:51-9.

6. Kim YK. The effect of group theraplay on self-esteem and depression of the elderly in day care center. Korea J Couns. 2011;12:1527-44.

7. Chung HJ. Music therapy: understanding and application. Seoul: Ehwa Womans University Press; 2005.

8. Burgener SC, Yang Y, Gilbert R, Marsh-Yant S. The effects of a multimodal intervention on outcomes of persons with early-stage dementia. Am J Alzheimers Dis Other Demen. 2008;23:382-94.

9. Carrie I, van Kan GA, Gillette-Guyonnet S, Andrieu S, Dartigues JF, Touchon J, et al. Recruitment strategies for preventive trials. The MAPT study (MultiDomain Alzheimer Preventive Trial). J Nutr Health Aging. 2012;16:355-9.

10. Shin SJ, Lee JS, Kim SK, Jeon BJ. The effect of a group occupational therapy on cognitive function and depression for mild dementia patients in a community. Korean J Occup Ther. 
2013;21:45-60.

11. Ngandu T, Lehtisalo J, Solomon A, Levalahti E, Ahtiluoto $\mathrm{S}$, Antikainen R, et al. A 2 year multidomain intervention of diet, exercise, cognitive training, and vascular risk monitoring versus control to prevent cognitive decline in at-risk elderly people (FINGER): a randomised controlled trial. Lancet. 2015;385:2255-63.

12. Kim SE, Park SM, Jung MY. Effects of a multimodal intervention program on cognitive function and depression of the elderly with early dementia. Korean J Occup Ther. 2017;25:4555.

13. Choi WS. The effects of group art therapy on cognitive functions and depression of the elderly with dementia. Korean J Art Ther. 2005;12:951-85.

14. Lee SH. A study on group art therapy program for elderly suicide prevention. Korean J Art Ther. 2011;18:153-71.

15. Lee YJ, Lee JH, Kim YJ, Yang NY, Park JH. The effect of multimodal intervention on quality of life, depression, and cognitive function in elderly people with dementia: a pilot study. J Korean Soc Occup Ther. 2014;22:85-97.

16. Ham MJ, Kim SK, Yoo DH, Lee JS. The effects of a multimodal interventional program on cognitive function, instrumental activities of daily living in patients with mild Alzheimer's disease.J Korean Soc Occup Ther. 2018;26:91-102.

17. Santos GD, Nunes PV, Stella F, Brum PS, Yassud MS, Ueno LM, et al. Multidisciplinary rehabilitation program: effects of a multimodal intervention for patients with Alzheimer's disease and cognitive impairment without dementia. Arch Clin Psychiatry. 2015;42:153-6.

18. Olazaran J, Reisberg B, Clare L, Cruz I, Pena-Casanova J, Del ST. Nonpharmacological therapies in Alzheimer's disease: a systematic review of efficacy. Dement Geriatr Cogn Disord. 2010;30:161-78.

19. Duru AG, Kapucu S. The effect of reminiscence therapy on cognition, depression, and activities of daily living for $\mathrm{pa}^{-}$ tients with Alzheimer disease. J Geriatr Psychiatry Neuro. 2016;29:31-7.

20. Kim OJ. Literature review on the benefits of companion animals to elderly persons. J Anim Assist Psychother. 2018;7:1731.

21. Hajar R. Animal-assisted therapy. Heart views. 2015;16:70-1.

22. Schneider N, Yvon C. A review of multidomain interventions to support healthy cognitive ageing. J Nutr Health Aging. 2013;17:252-7.

23. Kil TY. The effectiveness verification of integrated elderly play therapy for the older people living alone in a urban and rural complex area: focusing on the depression and interpersonal relationships.J Korean Gerontol Soc Wel. 2017;72:115-40.

24. Rodakowski J, Saghafi E, Butters MA, Skidmore ER. Non-pharmacological interventions for adults with mild cognitive impairment and early stage dementia: an updated scoping review. Mol Aspects Med. 2015;43-44:38-53.

25. Kim BS. The Effects of animal-assisted therapy on the self-esteem and life satisfaction in the elderly living alone [M.S. thesis]. Sanbon (Korea): Wonkwang University; 2019.

26. Sams MJ, Fortney EV, Willenbring S. Occupational therapy incorporating animals for children with autism: a pilot investigation. Am J Occup Ther. 2016;60:268-74.

27. Blender JA. A multimodal investigation of the use of animal assisted therapy in a clinical interview [Ph.D. thesis]. New York: University of Rochester Rochester; 2009.

28. Kim MI, Kang WG, Kim HJ, Ahn JW, Oh DR, Lee SY, et al. The effects of animal assisted activities program on the depression and self-expression in the elderly. J Anim Assist Psychother. 2018;7:33-42.

29. Fabel K, Wolf SA, Ehninger D, Babu H, Leal-Galicia P, Kempermann G. Additive effects of physical exercise and environmental enrichment on adult hippocampal neurogenesis in mice. Front Neurosci. 2009;3:50.

30. Kee BS. A preliminary study for the standardization of geriatric depression scale short form-Korea version. J Korean Neuropsychiatr Assoc. 1996;35:298-307.

31. Rosenberg M. Society and adolescent self-image. Princeton (NJ): Princeton University Press; 1965.

32. Jon BJ. Self-esteem: a test of it's measurability. Yonsei Nonchong. 1974;11:107-30.

33. Ahn SH, Lee SH, Kwon OS. Activation dimension: a mirage in the affective space. Korean J Soc Psychol. 1993;7:107-23.

34. Yamaguchi H, Maki Y, Yamagami T. Overview of non-pharmacological intervention for dementia and principles of brainactivating rehabilitation. Psychogeriatrics. 2010;10:206-13 .

35. Logsdon RG, McCurry SM, Teri L. Evidence-based interventions to improve quality of life for individuals with dementia. Alzheimers Care Today. 2007;8:309-18.

36. Graff MJ, Adang EM, Vernooij-Dassen MJ, Dekker J, Jonsson L, Thijssen M, et al. Community occupational therapy for older patients with dementia and their care givers: cost effectiveness study. BMJ. 2008;336:134-8.

37. Jones ML, Richmond S. Initial tooth movement: force application and pain-a relationship? Am J Orthod. 1985;88:111-6. 